\title{
Role of Multi-Detector Computed Tomography in Diagnosis and Staging of Cholesteatoma
}

\author{
MOHAMED S. SADEK, M.Sc.*; GEHAN S. SEIF EL-DEN, M.D.*; HAZEM ABUZEID, M.D.* and \\ MOHAMED SALEM, M.D.** \\ The Departments of Diagnostic Radiology* and Ear, Nose \& Throat (ENT)**, Faculty of Medicine, Assiut University, \\ Assiut, Egypt
}

\begin{abstract}
Background: Pathology of the middle ear is the third most common reason of visiting a general practitioner or a family doctor. In children and teenagers, inflammatory conditions of the middle ear are the most frequent reasons to prescribe antibiotics and perform surgery.

In the majority of these cases, proper diagnosis is made by clinical examination alone and patients will not benefit from additional diagnostic imaging studies. However, the prevalence of ear infections increased significantly and this may suggest that the current approach to preventing and treating middle ear inflammation is not adequate. Therefore, especially in complicated and recurrent conditions, imaging plays an important role; imaging findings may fundamentally influence the treatment. Also, in non-inflammatory conditions of external and middle ear Computed Tomography (CT) or Magnetic Resonance Imaging (MRI) would provide a diagnosis and/or necessary information for surgery in a significant number of cases.
\end{abstract}

Aim of Work: Evaluation the role of Multi-Detector Computed Tomography (MDCT) in diagnosis Chronic Suppurative Otitis Media (CSOM) with or without cholesteatoma and staging of middle ear Cholesteatoma and assess its impact on the selection of the surgical procedure.

Patients and Methods: A prospective study included 30 patients with mean age 30.4 years with CSOM with or without cholesteatoma. They were evaluated regarding to their clinical symptoms, temporal multidetector computed tomography findings, and postoperative results. MDCT staging classified cholesteatoma according to its site in the tympanic cavity (S); erosion of the ossicular chain $(\mathrm{O})$; and associated complications (C).

Results: MDCT imaging of these patients showed opacification of middle ear cavity with integrity of the ossicular chain with $100 \%$ accuracy. Nondependent soft tissue masses in the middle ear, eroded scutum $(n=20)$, eroded ossicles $(n=$ $20)$, intact tegmen tympani $(\mathrm{n}=30)$, lateral mastoid fistula $(n=2)$ and labyrinthine fistula $(n=1)$ were observed in CSOM with cholesteatoma. All these patients underwent surgical intervention that confirmed the diagnosis of the presence of

Correspondence to: Dr. Mohamed S. Sadek, The Department of Diagnostic Radiology, Faculty of Medicine,

Assiut University, Assiut, Egypt cholesteatoma in all these patients. But it also added the presence of lateral mastoid fistula and labyrinthine fistula in 1 other patient and discovered the presence of facial nerve injury in 1 patient.

Conclusion: MDCT scanning has limitations, but it is a useful in diagnosis, staging and surgical management of patients with middle ear Cholesteatoma.

Key Words: MDCT-CSOM-Cholesteatoma-Middle ear

\section{Introduction}

CHRONIC Suppurative Otitis Media (CSOM) is a potentially serious disease due to complications that may be life-threatening [1]. CSOM is a perforated tympanic membrane with persistent drainage from the middle ear lasting $>6-12$ week. Chronic suppuration can occur with or without cholesteato$\mathrm{ma}$, and the clinical history of both conditions can be very similar. The treatment plan for cholesteatoma always includes tympanomastoid surgery with medical treatment as an adjunct $[2,3]$.

Therefore, the clinician treating chronic otitis media must always have a high index of suspicion in order not to miss a critical diagnosis. Imaging studies, especially CT, can provide information regarding the anatomy of temporal bone and the extent of disease, which may not be apparent based on clinical findings alone [4].

Pre-operative Computed Tomography (CT) is an excellent technique for demonstrating even small abnormalities of the thin and complex bony structures of the middle ear, it is the modality of choice in the study of conductive hearing loss $[5,6]$

The incorporation of Multidetector Computed Tomography (MDCT), by reconstructing the image in any plane, with acquisition in few seconds and with a tolerable position for all patients, enables 
a detailed observation of the ear's anatomic repairs and progress [7]

The objectives of this study were to evaluate the role of MDCT in diagnosis of CSOM with or without cholesteatoma and staging of middle ear cholesteatoma and assess its impact on the selection of the surgical procedure.

\section{Patients and Methods}

A prospective study between May 2015 and May 2016 included 20 patients with mean age was $30.4 \pm 16.7$ years (range $17-75$ year). There were 18 males $(60 \%)$ and 12 females $(40 \%)$ who referred from Ear, Nose and Throat (ENT) outpatient clinic, Assiut University Hospital with middle ear symptoms. This study was approved by the local institutional review board and the Ethics Committee of our faculty. A written informed consent was obtained from all patients.

\section{Inclusion criteria:}

Patients in different sex and age groups with middle ear diseases.

\section{Exclusion criteria:}

- Any general contraindications of CT as pregnancy and renal impairment in case of contrast injection.

- Patients with history of previous operations.

\section{Methods:}

Pre-operative evaluation:

- Clinical evaluation by complete ENT examination.

- Laboratory evaluation before surgery.

- MDCT examination.

The non-contrast enhanced MDCT examination is performed on 16-row multidetector CT scan (Light Speed; GE Healthcare, Milwaukee, WI) by using a standard temporal bone protocol in the standard axial plane with helical technique and volumetric acquisition $(120 \mathrm{kv}, 200 \mathrm{~mA}$, rotation time of 0.8 seconds, thickness of the section of $0.6 \mathrm{~mm}, 0.3 \mathrm{~mm}$ reconstruction interval, and field of view of $240 \mathrm{~mm}$ and the CT dose average $1400 \mathrm{~m}$ $\mathrm{GYcm})$. The raw data were reconstructed by using a bone algorithm to provide optimal visualization of the bony anatomy of the temporal bone. The head of the patient was in a neutral position and the time of study was of 4 to 6 seconds. The scanning plan was parallel to the orbito-meatal line. Intravenous injection of $100 \mathrm{~mL}$ of nonionic contrast medium (nonionic Ultravist 370, Schering, Berlin, Germany) at a rate of $2 \mathrm{~mL}$ per second was carried out in 3 patients suspected to have intracranial complications.
- 2D Multiplanar Reformatted (MPR) for reconstruction and post-processing: The data analysis was performed on advantage workstation. The temporal bone was acquired in the axial plane and reformatted coronally with $1.0-\mathrm{mm}$ increments.

Cholesteatoma staged according to proposed Site-Ossicles-Complications (SOC) classification System 8 as followed:

S 1: If the cholesteatoma is restricted to the site where it had started.

S2: When the disease extends to another site.

S3: If it affects three sites.

S4: If it affects four sites.

S5: Cases in which the primary site is affected plus four or more sites are also involved.

Authors distinguished seven sites used in this classification: Attic, antrum, middle ear, mastoid, auditory tube, labyrinth and middle fossa.

O0: If the ossicle chain is intact.

O1: If incus is eroded but without chain discontinuity.

O2: If incus and stapes suprastructures are eroded.

O3: If the malleus head and incus are absent and stapes superstructure is eroded.

$\mathrm{C} 0$ : When there is no complication.

$\mathrm{C} 1$ : If there is one complication.

C2: If there are two or more complications.

Regarding complications, the authors considered lateral semicircular canal fistula, facial palsy, total sensorineural auditory loss, sinus thrombosis, and intracranial invasion.

Surgery:

According to the disease, the patients were subjected to different surgical procedures.

\section{Statistical analysis:}

Statistical Package for Social Sciences (SPSS) Version 20 for Windows (SPSS Inc.; Chicago, IL; USA), was used for data analysis. The patients' characteristics are expressed as ranges and means, (SDs) for continuous data and as frequencies (percentages) for categorical data. Sensitivity, specificity, positive, and negative predictive values and diagnostic accuracy were reported for pre-operative MDCT regarding the intraoperative results as the gold standard. 


\section{Results}

Computed tomography scans of 30 patients showed soft-tissue mass that filled the middle ear cavity completely or locally in the tympanic and atticoantral cavities. Intraoperative findings revealed the presence of soft tissue in each patient, showing that CT imaging had $100 \%$ consistency. No ossicular erosion was observed among group 1 patients while CT imaging of group 2 showed eroded scutum $(n=20)$, eroded ossicles $(n=20)$, intact tegmen tympani $(n=20)$, lateral mastoid fistula $(n=2)$, and labyrinthine fistula $(n=1)$. Figs. $(1,2)$ (Table 1).

All these patients underwent surgical intervention. In group 1 it confirmed the diagnosis of chronic otitis media and mastoiditis and exclude the presence of cholesteatoma. In group 2, it confirmed the diagnosis of the presence of cholesteatoma in all 20 patients of group 2. But it also

Table (1): Pre-operative MDCT and operative findings in 30 patients.

\begin{tabular}{|c|c|c|}
\hline Variable & $\begin{array}{l}\text { MDCT } \\
\text { findings }\end{array}$ & $\begin{array}{l}\text { Operative } \\
\text { findings }\end{array}$ \\
\hline \multicolumn{3}{|l|}{ Middle ear aeration: } \\
\hline Normal aeration & $0 \quad(0 \%)$ & $0 \quad(0 \%)$ \\
\hline Partial opacification & $12(40 \%)$ & $12(40 \%)$ \\
\hline Complete opacification & $18(60 \%)$ & $18(60 \%)$ \\
\hline \multicolumn{3}{|l|}{ Mastoid air cells: } \\
\hline Normal aeration & $6 \quad(20 \%)$ & $6 \quad(20 \%)$ \\
\hline Partial opacification & $2(6.7 \%)$ & $18(60 \%)$ \\
\hline Complete opacification & $20(66.6 \%)$ & $3(10 \%)$ \\
\hline Mastoid fistula & $2(6.7 \%)$ & $3(10 \%)$ \\
\hline \multicolumn{3}{|l|}{ Scutum: } \\
\hline Eroded & $11(36.7 \%)$ & $10(33.3 \%)$ \\
\hline Intact & $19(63.3 \%)$ & $20(66.7 \%)$ \\
\hline \multicolumn{3}{|l|}{ Ossicles: } \\
\hline Intact & $10(33.3 \%)$ & $10(33.3 \%)$ \\
\hline Partially eroded & $8 \quad(26.7 \%)$ & $8 \quad(26.7 \%)$ \\
\hline Completely eroded & $12(40 \%)$ & $12(40 \%)$ \\
\hline \multicolumn{3}{|l|}{ Tegmen tympani: } \\
\hline Intact & $30(100 \%)$ & $30(100 \%)$ \\
\hline \multicolumn{3}{|l|}{ Facial nerve injury: } \\
\hline Yes & $0 \quad(0 \%)$ & $1 \quad(3.3 \%)$ \\
\hline No & $30(100 \%)$ & $29(96.7 \%)$ \\
\hline \multicolumn{3}{|l|}{ Labyrinthine fistula: } \\
\hline Yes & $1 \quad(3.3 \%)$ & $2(6.7 \%)$ \\
\hline No & $29(96.7 \%)$ & $28(93.3 \%)$ \\
\hline
\end{tabular}

added the presence of lateral mastoid fistula and labyrinthine fistula in 1 other patient Fig. (3) and discovered the presence of facial nerve injury in 1 patient (Table 1). No intracranial extension was observed.

Pre-operative MDCT can detect middle ear aeration, ossicular and scutum erosions in all 30 patients that was consistent with operative results giving $100 \%, 100 \%$ and $100 \%$ specificity, sensitivity and diagnostic accuracy respectively.

Regarding mastoid air cells, MDCT depict normal aeration in 6 patients with $100 \%$ accuracy, while partial opacification and complete opacification had $42.9 \%, 100 \%$ specificity respectively and $100 \%, 13 \%$ sensitivity respectively and $46.7 \%$ and $36.7 \%$ accuracy respectively.

The staging of cholesteatoma was summarized in (Table 3).

Table (2): Diagnostic accuracy of pre-operative MDCT compared to operative results.

\begin{tabular}{|c|c|c|c|c|c|}
\hline & $\begin{array}{l}\text { Sensi- } \\
\text { tivity }\end{array}$ & $\begin{array}{l}\text { Speci- } \\
\text { ficity }\end{array}$ & PPV & NPV & $\begin{array}{l}\text { Accu- } \\
\text { racy }\end{array}$ \\
\hline \multicolumn{6}{|l|}{ Middle ear: } \\
\hline - Normal aeration & 100.0 & 100.0 & 100.0 & 100.0 & 100.0 \\
\hline - Partial opacification & 100.0 & 100.0 & 100.0 & 100.0 & 100.0 \\
\hline - Complete opacification & 100.0 & 100.0 & 100.0 & 100.0 & 100.0 \\
\hline \multicolumn{6}{|l|}{ Mastoid air: } \\
\hline - Normal aeration & 100.0 & 100.0 & 100.0 & 100.0 & 100.0 \\
\hline - Partial opacification & 100.0 & 42.9 & 11.1 & 100.0 & 46.7 \\
\hline - Complete opacification & 13.6 & 100.0 & 100.0 & 29.6 & 36.7 \\
\hline - Scutum erosions & 100.0 & 100.0 & 100.0 & 100.0 & 100.0 \\
\hline \multicolumn{6}{|l|}{ Ossicles: } \\
\hline - Intact & 100.0 & 100.0 & 100.0 & 100.0 & 100.0 \\
\hline - Partially eroded & 100.0 & 100.0 & 100.0 & 100.0 & 100.0 \\
\hline - Completely eroded & 100.0 & 100.0 & 100.0 & 100.0 & 100.0 \\
\hline
\end{tabular}

Table (3): The stage of cholesteatoma.

\begin{tabular}{ccccc}
\hline Variable & O0 & O1 & O2 & O3 \\
\hline S1 & & & \\
S2 & & & \\
S3 & & & 6 cases \\
S4 & 5 cases & 8 cases & 7 cases \\
S5 & & & 4 cases \\
\hline
\end{tabular}



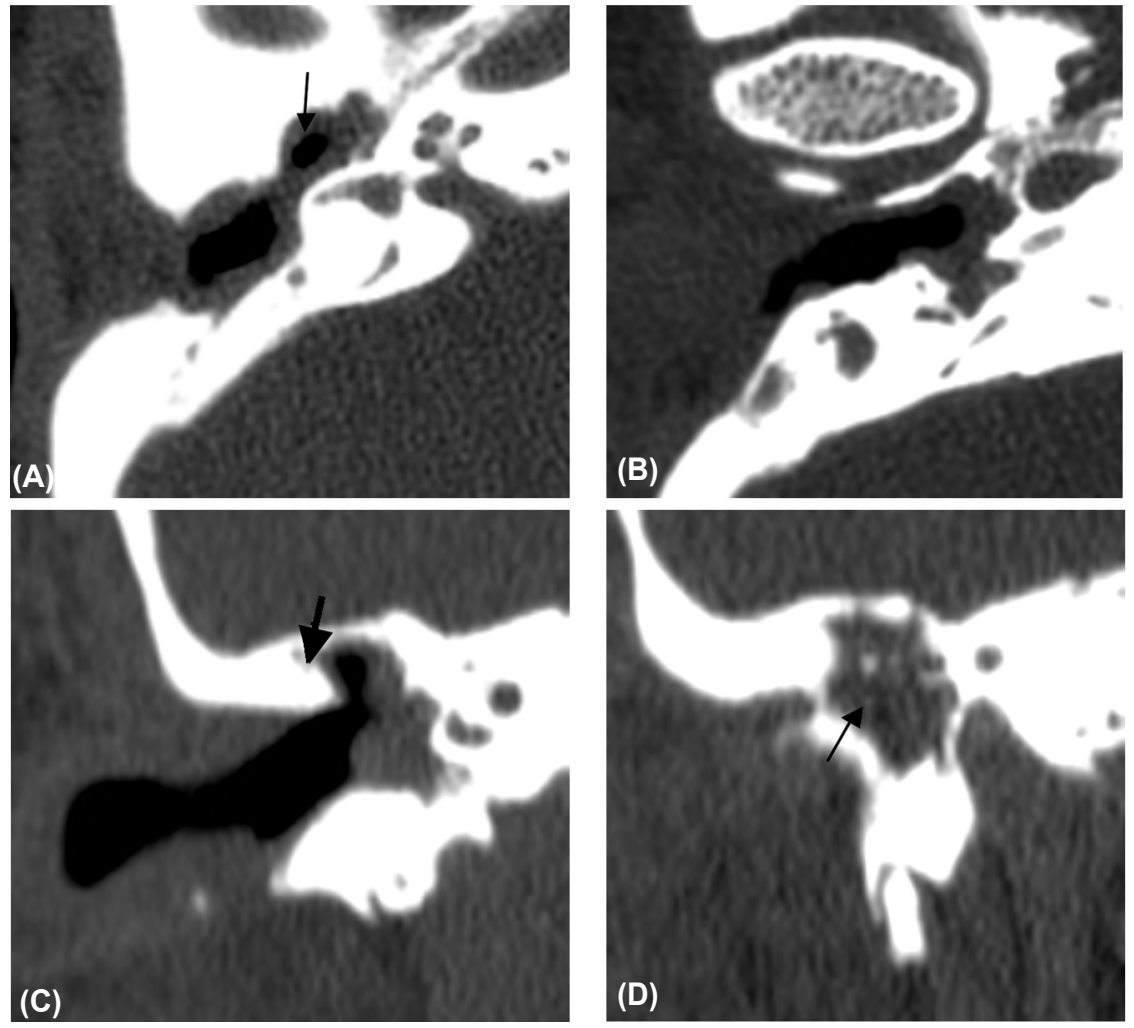

Fig. (1): A 34-years old female patient complaint from right ear discharge. MDCT axial image (A,B) and coronal reformatted image (C,D) showed near total opacification of the right middle ear cavity, complete erosions of the ossicles (A,B), eroded scutum (C, short black arrow) and complete opacification of the right mastoid air cells with loss of the fibrous septae (D, long black arrow). Post-operative data confirmed the presence of right sided cholesteatoma (stage $55 \mathrm{O} 3 \mathrm{C} 2$ ) with lateral mastoid fistula and labyrinthine fistula.

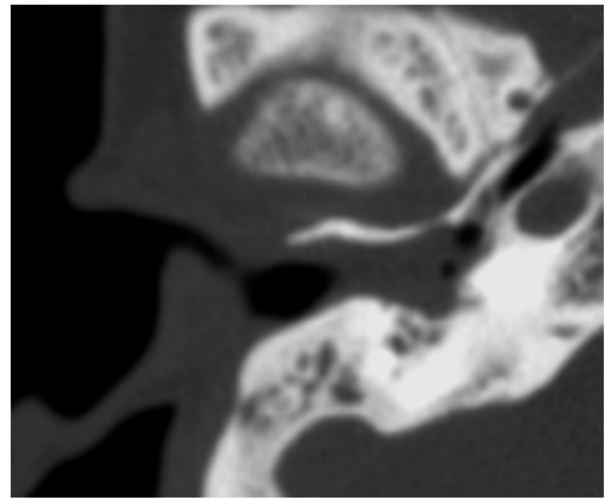

(A) (Axial Rt side)

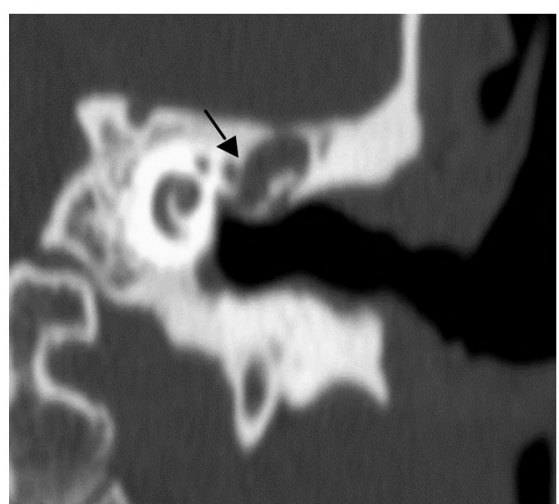

(C) (Axial Lt side)

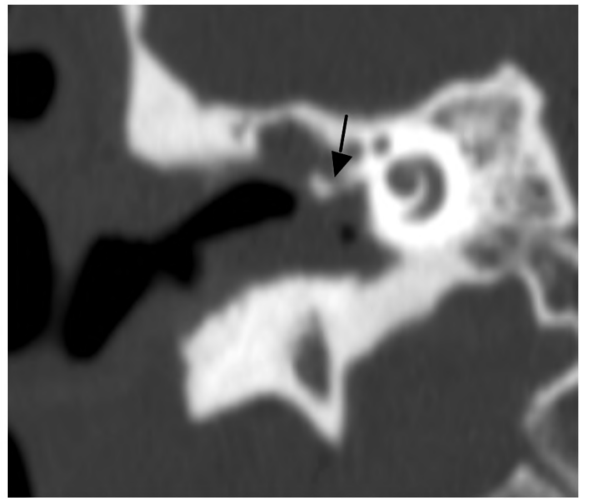

(B) (Coronal Rt side)

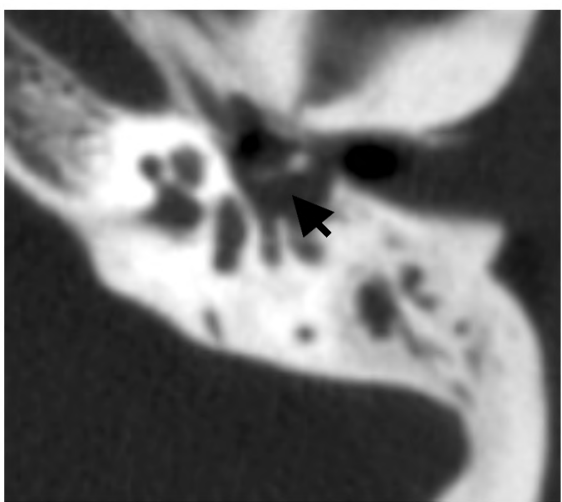

(D) (Coronal Lt side)

Fig. (2): A 30-years male patient complaint from bilateral ear discharge. Axial and coronal reformatted MDCT images (A-D) showed bilateral complete opacifications of the middle ear cavities and mastoid air cells bilaterally eroded scutum and bilaterally partially eroded ossicles (except stapes on the right side, B and malleolus on the left side, $\mathrm{C}$ black arrows). Post-operative data confirmed the presence of bilateral cholesteatoma stage (RT side: Stage S4 O3 C0, Lt side: Stage S4O2C0). 

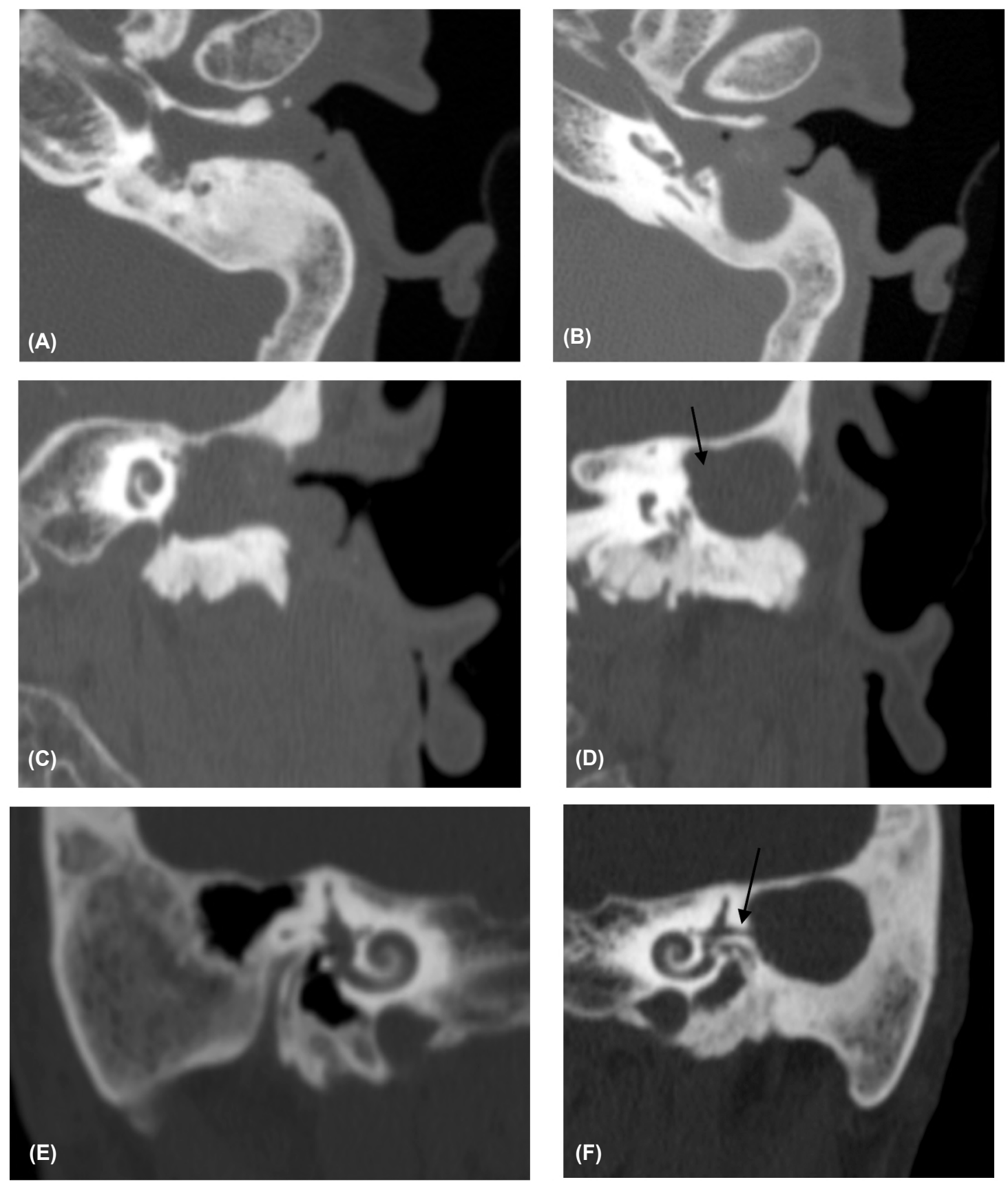

Fig. (3): A 40-years male patient presented by left purulent ear discharge for 1-year duration. Axial and coronal reformate MDCT images (AD) showed complete opacification of the left middle ear cavity, the left mastoid air cells occupied by soft tissue mass lesion with destruction of the fibrous septae (black arrows), eroded scutum, completely eroded ossicles, intact tegmen tympani. Oblique coronal reformatted right normal side (E) and left diseased side (F) revealed left labyrinthine fistula (black arrow) and facial nerve injury. Post-operative data confirmed the presence of left sided cholesteatoma with left mastoid fistula and added the presence of left labyrinthine fistula and left facial nerve injury (stage $\mathrm{S} 5 \mathrm{O} 3 \mathrm{C} 2$ ).

\section{Discussion}

CSOM still prevails as one of the most common otological problems encountered worldwide especially in the developing countries, neglect of the disease causes progression to cholesteatoma formation and complications. Modern high-resolution MDCT have allowed for earlier diagnosis when signs and symptoms are present. CT produces excellent images of middle ear soft-tissue masses and appears to be the diagnostic method of choice for cholesteatomas. CT images provide a more precise definition of the anatomic extent of the disease of the middle ear and the relationship of cholesteatoma masses to the contiguous structures [9]. 
CSOM without cholesteatoma is indicated on MDCT when air cells appear opaque by soft tissue or fluid densities but maintain their normal trabecular pattern or whenever there is obliteration of mastoid antrum and periantral cells by increased reactive bone formation sclerosis [10]. In our series, 10 patients had these CT features. These were confidently labeled as CSOM. Complete opacification of the middle ear with no bony destruction makes radiologic differentiation of cholesteatoma from middle ear effusions and granulation tissue difficult, if not impossible [10,11]. The presence of an air-fluid level or a soft tissue (fluid) mass in the dependent portion of the middle ear would render support to a diagnosis of effusion [10]

One of the important advantages of the MDCT scan is the detection of early cholesteatoma with subtle bony erosion or ossicular displacement. This early detection by CT scan with the use of a simple noninvasive surgical technique (atticotomy) can preserve hearing [12]. Cholesteatoma in hidden areas, such as the posterior tympanic recess, may be revealed by CT even if it is not detected by otologic examination [13].

In the current study, non-dependent, homogeneous and polypoidal soft tissue densities were present in the mastoid antrum and middle ear cavity. In some of our cases, soft tissues occupied all spaces at the time of CT study with antral expansion, abutting the ossicular chain and bulging into the external auditory meatus. These patients were considered as having equivocal features with possibility of CSOM and possibility of associated cholesteatoma. Our study showed that all patients with cholesteatoma had at least one of the CT criteria indicating cholesteatoma. We observed cholesteatoma formation in 20 patients with scutum erosions $(n=20 / 30)$ and loss of the ossicular integrity $(n=20 / 30)$ of cases. MDCT revealed these findings with $100 \%$ accuracy. this was in agreement with Mahmuto glu et al., [14] who reported that MDCT revealed these findings with $100 \%$ sensitivity and they concluded that the best diagnostic indicator of a cholesteatoma is a mass-like soft tissue located in a retraction pocket in the posterosuperior quadrant of the Shrapnell membrane, causing widening of Prussak space and scutum erosion. Also, Chee and Tan [15] who concluded in their series of 36 patients that 34 patients (94.4\%) had been correctly diagnosed by CT.

The literature reports various rates regarding the preoperative evaluation of ossicular chain destruction via $\mathrm{CT}$. In the current study, the entire ossicular chain erosion occurred in all patients with cholesteatoma. The literature presents the same frequency, with sensitivity ranging from $80 \%$ to $100 \%$ [16]. El-Essawy et al., [17] in a series of 32 cases concluded that temporal bone complications including bone erosion and cavity formation were seen in all patients with cholesteatoma (100\%) which was similar to our study.

On the other hand, many otologists emphasize the difficulty of evaluation, especially the stapes destruction [18-21]. Mahmuto glu et al., [14] observed destruction of malleus at rate of $86 \%$, incus at $84 \%$, and stapes at $54 \%$ and the entire ossicular chain at rate $68 \%$. In our series, we observed destruction of entire ossicular chain in $55 \%$ while both incus and stapes in $30 \%$ of patients.

In our series, well-pneumatised mastoid was seen in $20 \%$, sclerotic in $66.6 \%$ and partial pneumatized in remaining $6.7 \%$. These values are comparable to studies by Rai 22 who found wellpneumatised mastoid in $44 \%$ and poorly pneumatised in 56\% patients with $100 \%$ sensitivity and specificity to know the type of mastoid pneumatisation. This agreed with our current findings. Also, Razek et al., [23] reported 79\% sensitivity of MDCT for detection of mastoid involvement.

Complications of cholesteatoma occur when the lesion erodes the anatomical boundaries of the middle ear, antrum, and mastoid or involves the facial nerve. The most common complications are lateral semicircular canal fistula, facial canal erosion, and tegmen tympani erosion [14].

No intracranial complications were detected in all 30 patients. In the current study, integrity of tegmen tympani was assessed by MDCT with accuracy $100 \%$. This was in agreement with Mahmuto glu et al., [14] who reported that CT scan was highly sensitive for dural height with nearly $100 \%$ sensitivity.

Overall sensitivity of associated complication was $60 \%$ in the current study, as Labyrinthine fistula with involvement of the lateral semicircular canal was reported in $6.7 \%$ of patients with cholesteatoma similar to Razek et al., [23] series findings that was $7 \%$. It agreed with Baráth and fellows 24 concluded in their study that the labyrinthine fistula may occur with a prevalence of $5-10 \%$ of patients with chronic ear infection due to cholesteatoma.

A dehiscence of the bony canal of the facial nerve was observed only intraoperatively in 3.3\% of our series. However, minor bony defects may stay undetected because of multiplanar and tortuous 
route of the facial canal. Multiple planes of view are necessary for an optimal image of the canal [25] . Fuse et al., [26] have found that computerized tomography coincided with surgical findings in $75 \%$ of cases with $66 \%$ sensitivity and $84 \%$ specificity.

David et al., [27] stated that pre-operative demonstration of facial nerve canal involvement was often difficult not only because of the small size of the facial nerve canal but also due to its oblique orientation and the presence of developmental dehiscence.

There are a few limitations of this study. First, the study included a small number of patients; second; this study was conducted on 16 multidetector CT scanners. Using of higher multidetector CT scanners may improve the image quality and help to assess the role of 3D and VR reconstruction in middle ear pathologies and their complication.

MDCT is helpful in determining the anatomy of the middle ear and mastoid and the extent of the disease. In addition, MDCT scanning serves as a road map to assist the surgeon during cholesteatoma surgery. Although MDCT cannot reliably distinguish cholesteatoma from mucosal disease and fluid, coexistence of soft tissue density in the epitympanic region and bone erosion is suggestive of cholesteatoma. We concluded that pre-operative MDCT has limitations, but it is a useful adjunct for the surgical management of patients with middle ear diseases.

\section{Conclusion:}

Several conclusions were derived based on our study results:

- MDCT is helpful in determining the anatomy of the middle ear and mastoid and the extent of the disease.

- MDCT scanning is a unique method of detection of early cholesteatoma as well as detection of cholesteatoma in hidden areas. In addition, MDCT scanning serves as a road map to assist the surgeon during cholesteatoma surgery.

- MDCT cannot reliably distinguish cholesteatoma from mucosal disease and fluid.

- Coexistence of soft tissue density in the epitympanic region and bone erosion is suggestive of cholesteatoma.

- MDCT occasionally gives the erroneous impression of lateral semicircular canal fistulization, tegmen tympani erosion, and facial nerve involve- ment due to volume averaging of the thin bony covering of these structures with adjacent soft tissues.

- MDCT may affect the decision regarding the type of operation (mastoid pneumotisation, attic blockage/intact canal wall, canal wall down, atticoantrotomy) and can provide surgeons with a warning about possible difficulties due to anatomical variations (e.g., low-lying dura, anteriorly placed sigmoid sinus). This could help prevent surgical complications.

We conclude that MDCT scanning has limitations, but it is a useful adjunct for the surgical management of patients with middle ear diseases.

\section{References}

1- MUSTAFA A., HETA A., KASTRATI B., et al.: Complications of chronic otitis media with cholesteatoma during a 10-year period in Kosovo. Eur. Arch. Otorhinolaryngol., 265: 1477-82, 2008.

2- MATSUDA Y., KURITA T., UEDA Y., ITO S. and NAKASHIMA T.: Effect of tympanic membrane perforation on middle-ear sound transmission. J. Laryngol. Otol., May 123 (Suppl 31): 81-9. [Medline], 2009.

3- WRIGHT D. and SAFRANEK S.: Treatment of otitis media with perforated tympanic membrane. Am. Fam. Physician, Apr. 15.79 (8): 650, 654, 2009.

4- BLEVINS N.H. and CARTER B.L.: Routine pre-operative imaging in chronic ear surgery. Am. J. Otol., 19: 527-35; discussion 535-8, 1998.

5- DHOOGE I.J., VANDENBUSSCHE T. and LEMMER LING M.: Value of computed tomography of the temporal bone. Rev. Laryngol. Otol. Rhinol. (Bord), 119 (2): 914, 2001.

6- YATES P., FLOOD L.M., BANERJEE A., et al.: CT scanning of cholesteatoma: What does the surgeon want to know? Br. J. Radiol., 75: 847Y852, 2002.

7- RYDBERG J., BUCKWALTER K.A., CALDEMEYER K.S., et al.: Multisection CT: Scanning techniques and clinical applications [review]. Radiographics, 20: 1787Y1806, 2000.

8- SALEH H.A. and MILLS R.P.: Classification and staging of cholesteatoma. Clin. Otolaryngol. Allied. Sci., 24: 3559, 1999.

9- FUJII N., INUI Y. and KATADA K.: Temporal bone anatomy: Correlation of multiplanar reconstruction sections and three-dimensional computed tomography images. Jpn. J. Radiol., Nov., 28 (9): 637-48, 2010.

10- LIU D.P. and BERGERON R.T.: Contemporary radiologic imaging in the evaluation of middle ear-attic-antral complex cholesteatomas. Otolaryngol. Clin. North Am., 22: 897-909, 1989.

11- MAFFE M.F., LEVIN B.C., APPLEBAUM E.L., CAMPOS M. and JAMES C.F.: Cholesteatoma of the middle ear and mastoid. A comparison of CT scan and operative findings. Otolaryngol. Clin. North Am., 21: 265-93, 1988. 
12- SEEMA GUL, UMMARA SIDDIQUE UMER MUHAMMAD SALEEM KHAN, SHAHJEHAN ALAM, SARAH JAVED and SYED GHUAS: Detection of temporal bone cholesteatoma by multidetector computed tomography. J.P.M.I., 133-40, 2016

13- LEMMERLING M.M., De FOER B., VERBIST B.M., et al.: Imaging of inflammatory and infectious diseases in the temporal bone. Neuroimaging. Clin. N. Am., 19: 321Y337, 2009.

14- MAHMUTOGLU A.S., CELEBI I., SAHINO GLU S., CAKMAKÇI E. and SÖZEN E.: Reliability of preoperative multidetector computed tomography scan in patients with chronic otitis media. J. Craniofac. Surg., Jul., 24 (4): 1472-6. doi: 10.1097/SCS.0b013e31829031b1, 2013.

15- CHEE N.C. and TAN T.Y.: The value of pre-operative high resolution CT scans in cholesteatoma surgery. Singapore Med. J., 2: 155-9, 2001.

16- GAURANO J.L. and JOHARJY I.A.: Middle ear cholesteatoma: Characteristic CT findings in 64 patients. Ann. Saudi Med., 24: 442-7, 2004.

17- EL-ESSAWY S., EL-NAHAS M., EL-SHEWAHY H. and GHONIEM M.R.: Complicated middle ear cholesteatoma, a CT study. Egypt J. Radiol. Nucl. Med., 23: 161-70, 1992.

18- ALZOUBI F.Q., ODAT H.A., AL-BALAS H.A., et al.: The role of pre-operative CT scan in patients with chronic otitis media. Eur. Arch. Otorhinolaryngol., 266: 807-9, 2009.

19- MAFEE M.F., KUMAR A., YANNIAS D.A., et al.: Computed tomography of the middle ear in the evaluation of cholesteatomas and other soft-tissue masses: Comparison with pluridirectional tomography. Radiology, 148: 46572, 1983.

20- BANERJEE A., FLOOD L.M., YATES P., et al.: Computed tomography in suppurative ear disease: Does it influence management? J. Laryngol. Otol., 117: 454-8, 2003.

21- O'REILLY B.J., CHEVRETTON E.B., WYLIE I., et al.: The value of CT scanning in chronic suppurative otitis media. J. Laryngol. Otol., 105: 990-4, 1991.

22- RAI T.: Radiological study of the temporal bone in chronic otitis media: Prospective study of 50 cases. Indian Journal of Otology, 20 (2): 48-55, 2014.

23- RAZEK A.A., GHONIM M.R. and ASHRAF B.: Computed Tomography Staging of Middle Ear Cholesteatoma. Pol. J. Radiol., Jun. 25, 80: 328-33. doi: 10.12659/ PJR.894155. eCollection 2015.

24- BARÁTH K., HUBER A.M., STÄMPFI P., VARGA Z. and KOLLIAS S.: Neuroradiology of cholesteatomas. AJNR., 32: 221-9, 2011.

25- VALAVANIS A., KUBIK S. and OGUZ M.: "Exploration of the facial nerve canal by high-resolution computed tomography: Anatomy and pathology," Neuroradiology, 24 (3): 139-47, 1983

26- FUSE T., TADA Y., AOYAGI M. and SUGAI Y.: CT detection of facial canal dehiscence and semicircular canal fistula: Comparison with surgical findings. Journal of Computer Assisted Tomography, 20 (2): 221-4, 1996.

27- DAVID C., LIA D., THOMAS R. and BERGERON M.: Contemporary radiologic imaging in the evaluation of middle ear-attic-antral complex cholesteatoma. Otolaryngol. Clin. North Am., 22: 897-909, 1989.
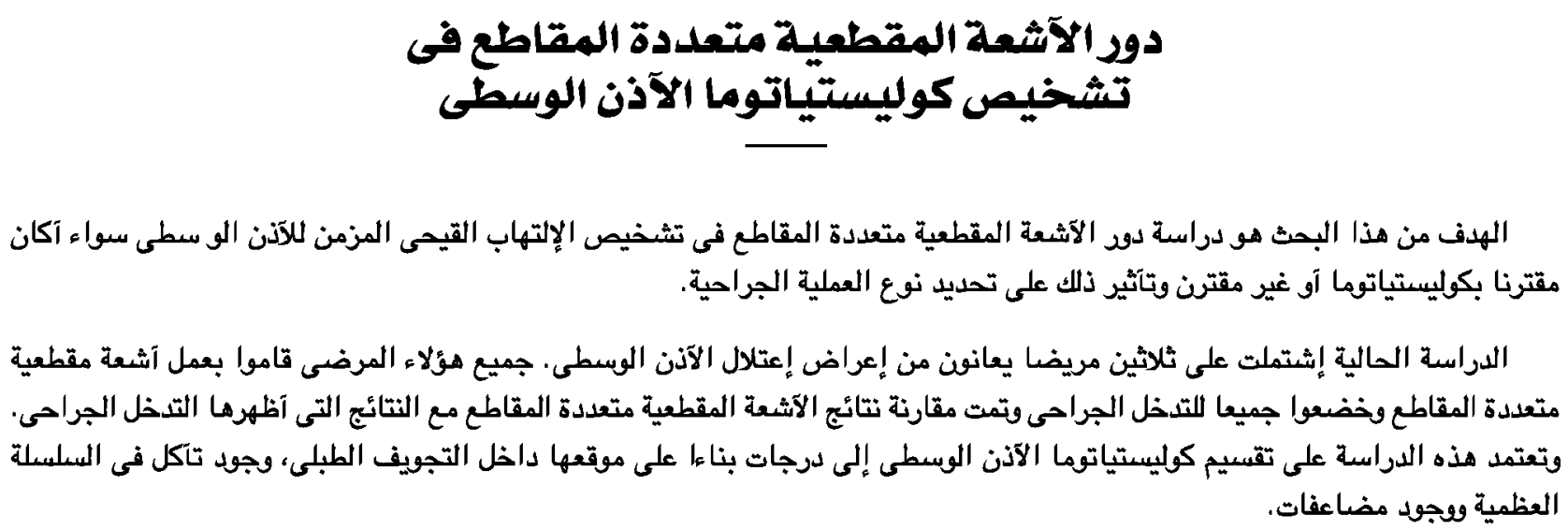